\title{
A Study to Evaluate Key Indicators of Prescription for Cvs and Gi Medications in Tertiary Care Teaching and District Hopitals of East Sikkim
}

\author{
Dr Prakash Tomar, Dr Namgay Bhutia, Dr Ghanashyam Luitel, Dr S Varun \\ Satpathy
}

\section{Introduction}

Medicines account for a substantial part of household expenditure. The overall budget of medicines varies widely in different states in India. The expenditure pattern of medicines of the state government shows that there is a wide range of difference across the states during 2001-2002. In all, roughly $10 \%$ of the total health budget goes into procuring medicines in India. Even then, availability of required medicines often is a big issue. The essential drugs list can help the country to rationalize the purchasing and distribution of medicines, thereby reducing costs to the health system (Sitanshu S, Himanshu S, et. al).

Each drug treatment should include for each health problems, the name, dosage form, strength, average dose (paediatric and adult), number of doses per day, and number of days of treatment (STG, 2007). In the United Kingdom, in 1999, a joint formulary for primary and secondary care was developed and Separate budgets used to exist for primary and secondary care as the patient's transition between the two sectors was problematic. There were divisions in managing prescriptions between primary and secondary care. They felt that joint formularies would improve overall care and raise awareness of the need to consider overall costs within a unified national health service (Duerden \& Walley).

A study done by the Advanced Concepts Institute, in Philadelphia, United States of America found that both predominantly e-prescribers and traditional prescribers showed high levels of formulary compliance of $83.2 \%$ and $82.8 \%$ respectively. They also found that there was no difference in generic drug utilisation rates between e prescribers and traditional prescribers (Ross et. al, 2005). Cost minimization is usually the reason for formularies as well as the promotion of rational prescribing. Traditionally, formulary systems have also been used to control drug costs (Wade et al., 1996).

Medical aids also formulate their own formularies. This poses a problem for physicians in private practise, as they see patients from varying medical aids, each with its own formulary. Physicians therefore have to deal with many formularies while prescribing (Shrank et.al, 2004).

Prescription audit is a "guide to good prescription" or the process or mechanism of evaluating data related to providing the right medicine to right people at right time and right doses form, in respect to a central priority of health core. The way to ensure this is through the effective implementation of the WHO's recommendation on rational drug policies (ACE vision health consultants).

Managerial interventions in the form of self monitoring programmes on prescribing habits, in which prescribing patterns were compared and then fed back to the prescribers, showed positive results in different health centres in Indonesia. Poly pharmacy decreased, prescribing patterns improved, the average number of drugs per prescription decreased from 4.2 to 3.1 (Laing \& Santoso, 2004). Irregular prescribing of drugs is a major health concern in developing country like India. High power salesmanship also plays a key role in the prescribing behaviour of doctors (Mohanty BK et, al).

Study carried out to evaluate the prescription rationality and drug prescribing practice of physicians in east Godavari, Andra Pradesh, India, reported that only $16.8 \%$ of prescription contained fixed dose combination (T. M.Vijayakumar, et. al).

A prescription audit carried out in secondary level Government hospitals in Maharashtra, India, reported that the average number of drug/prescription was $3.1 \%$, and $23 \%$ of the prescribed drugs were in combination (Potharaju, et. al)

A prescription audit study in Garhwal (Uttaranchal), India, reported that the average number of drugs per prescription was 3.65\% and FDCs were 59\% (Rishi RK, et. al).

A prescribing pattern in a pediatric out-patient in Gujarat, India, reported that the average numbers of medicines per prescription was 3.72\%, FDCs were 47.7\%, (Nazima Y Mirza, et. al).

The present study was undertaken to document the utilization of cardiovascular and gastrointestinal medication by knowing the number of drugs per encounter, number of injectable preparation, cost per prescription and number of fixed dose combination prescribed and to generate information on the core 
prescribing indicators proposed by the WHO, in cardiovascular and gastrointestinal medications in urban hospitals of Sikkim.

\section{Aims And Objectives}

To evaluate prescription of cardiovascular and gastrointestinal medication by knowing the number of drugs per encounter, number of injectable preparation, cost per prescription and number of fixed dose combination prescribed.

\section{Materials And Methods}

1. Setting: The study was conducted in the Department of Medicine, Singtam District Hospital and Central Referral Hospital, Tadong, Gangtok.

2. Type of Study: Prospective prescription audit; Survey and collection of information was obtained from actual prescriptions which were accessed from the OPD and pharmacy after the patient finished physician consultation.

3. Method: i. Collection of information from prescriptions from OPD and pharmacy.

ii. Operational modality - The focal point of collection of the data were prescriptions at the hospital OPD / pharmacy of CRH and Singtam District Hospitals. The numbers of the prescriptions that contain treatment for cardiovascular and gastrointestinal diagnosis were selected for the study. Necessary information, as given below, was noted for each prescription in a case record form devised for the study. Further, some sociodemographic information were collected from the patient and entered in the case record form. Therefore, the case record form was a replica of each prescription. Relevant information from prescribing physicians was also collected. Each case record form was authenticated on a daily basis by the researchers. Information thus collected was entered in MS Excel database on a regular basis for ease of statistical analysis at a later date. Verbal information was provided to each patient and prescribing physicians regarding the purpose of collection of information contained in the prescriptions and confidentiality was ensured. Before commencement of the study, written approval to conduct the study was obtained from the Medical Superintendents and Heads of respective departments from both Singtam District and CRH Hospitals. The study protocol was approved by the Institutional Ethics Committee (IEC) of Sikkim Manipal Institute of Medical Sciences, Gangtok.

4. Data Collection: Each case record form (CRF) contained the following information.

Patient biodata

Diagnosis

Number of drugs / prescription

Number of injectable preparations

Fixed dose combination

Duration of treatment

Cost per prescription

Duration of study: December 2011 - November 2013 (2 Years)

Sample Size: The researcher calculated the average number of items dispensed at each dispensing site for the period December 2011 to November 2013. Overall, an average number of 1152 prescriptions were dispensed during the study period from the new case registered with cardiovascular and gastrointestinal diseases at both hospitals in two years, to detect a minimum 5\% prescriptions following the EDL and STG with an upper limit of $10 \%$ at a confidence interval of $95 \%$ a minimum sample size of $n=136$ was required.

Statistics: As most variables are non-continuous we used non-parametric tests for analysis of significance. Commonly Chi-Square test was used and $\mathrm{p} \leq 0.05$ was considered as significant. Data was initially entered in Excel files and later analyzed by SPSS 20.0.

\section{Result}

The present study was undertaken to evaluate data on cardiovascular and gastrointestinal medications in urban hospitals of Sikkim. The main aim of our study is to audit the prescriptions for number of drugs per encounter, number of injectable preparations, cost per prescription and fixed dose combination prescribed. Our study revealed that 2.13 drugs were prescribed per prescription, no injectables were prescribed in any of the prescription given upon OPD basis. Overall the cost per prescription was 181.73 Rs. Out of the total prescription $65.8 \%$ were fixed dose combination preprations and $34.2 \%$ was not fixed dose combination preprations. 
A Study to Evaluate Key Indicators of Prescription for Cvs and Gi Medications in Tertiary ....

\begin{tabular}{|ll|r|r|r|r|}
\hline Identifications & Number_drugs & Duration & Cost & \multicolumn{1}{c|}{ Years } \\
\hline \multirow{5}{*}{ Singtam } & Mean & 2.34 & 24.10 & 216.76 & 12.25 \\
& $\mathrm{~N}$ & 493 & 493 & 493 & 493 \\
& Std. Deviation & .793 & 9.092 & 103.809 & 5.654 \\
& Minimum & 1 & 5 & 26 & 2 \\
& Maximum & 4 & 30 & 789 & 17 \\
& Mean & 1.96 & 16.08 & 146.71 & 5.82 \\
& N & 657 & 658 & 658 & 658 \\
Gangtok & Std. Deviation & .877 & 9.995 & 99.910 & 2.243 \\
& Minimum & 1 & 3 & 10 & 2 \\
& Maximum & 4 & 70 & 612 & 17 \\
& Mean & 2.13 & 19.51 & 176.71 & 8.58 \\
& N & 1150 & 1151 & 1151 & 1151 \\
& Std. Deviation & .862 & 10.401 & 107.311 & 5.166 \\
& Minimum & 1 & 3 & 10 & 2 \\
& Maximum & 4 & 70 & 789 & 17 \\
\hline
\end{tabular}

$P$ value is significant as it is < than .001

Cost per prescription: After evaluation, the cost/prescription, were Rs 216.76 in district hospital, Singtam and Rs 146.71 in CRH respectively. Overall, the cost/prescriptions in both the hospitals were Rs 181.73 .

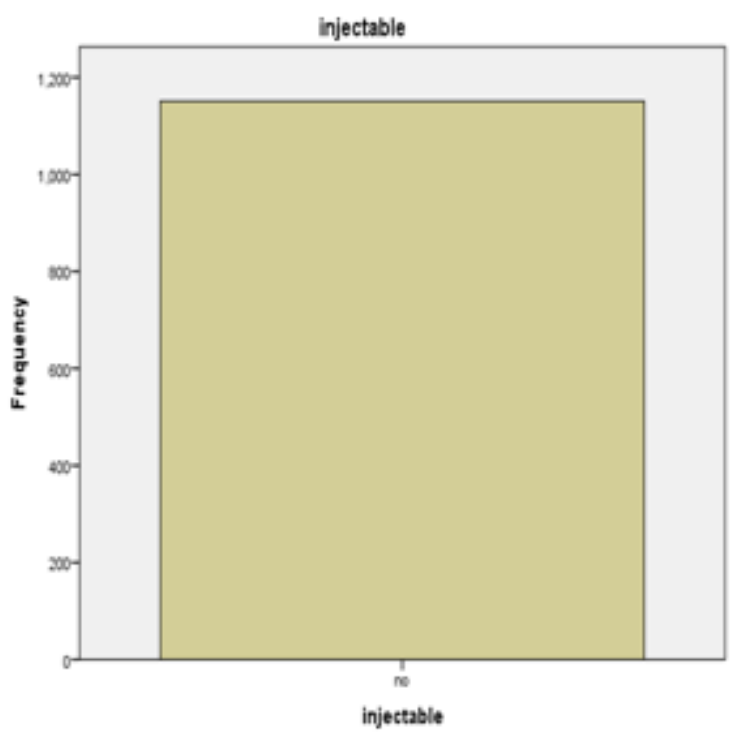

Injectable preparations were not prescribed in any of the prescription given upon

daily OPD basis

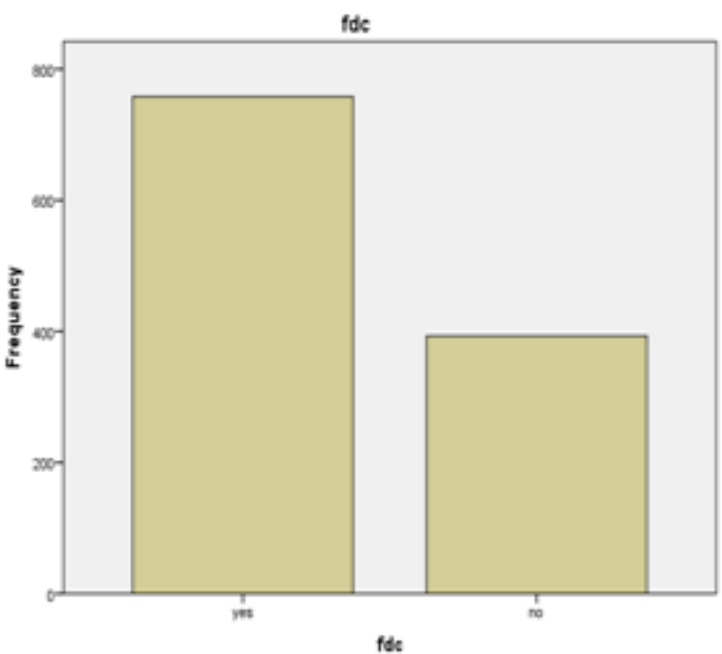


$\mathrm{P}$ value of fixed dose combinations is $<0.001$.

Fixed dose combinations: Out of total prescriptions $65.8 \%$ (758) of the prescriptions were prescribed in fixed dose combination therapy whereas only $34.2 \%$ (394) of the prescriptions were not prescribed by fixed dose combinations

\section{Summary And Conclusion}

1. $\quad 65.8 \%$ of the prescriptions were prescribed in FDCs.

2. Cost of the prescriptions on an average was Rs 181.73 per prescription and all were given in oral tablet

form.

3. Drugs per prescription were around 2.34/prescription which is quite higher than WHO guideline-1.61.8 (WHO, 2009).

Our study revealed that majority of prescriptions had fixed dose combination drugs, cost per prescription was

Rs.181.73/prescription and drugs per prescription was around 2.34.

\section{Limitations}

1. Our study was based on data collected from two major hospitals of Sikkim, so it is very likely that these data do not represent the whole population of Sikkim.

2. The selection of the patients in our study was random, data were not analyzed according to the age and income of the patient, as the data were not mentioned in the prescriptions, so it is very likely that we might have missed a particular age and income groups of the patient.

3. We have audited just the OPD prescriptions but not the indoor ones because it was excluded from the present study, hence, there might be the reason of some degree of bias.

\section{Suggestions}

1. Inpatients data should also have been analyzed to look into the number of injectable preparations.

2. FDC should be avoided; it should be less than $11 \%$ as per WHO guideline (WHO, 2007).

3. To introduce a managerial, monitoring tool or system for prescribing from NLEM.

4. To provide training on effective prescribing and rational use of medicine for nurses and doctors to reduce the polypharmacy \& FDCs.

\section{Bibliography}

[1]. Sitanshu Sekhar Kar, Himashu Sekhar Pradhan, Guru Prasad Mohanta: The concept of essential medicines \& rational use in public: Indian Journal of Community Medicine, vol. 35, issue 1, 2010. Downloaded from: http://www.ijcm.org.in/article.asp?issn=09700218

[2]. Drug and Therapeutics committees - A Practical Guide: 3. Managing the formulary process: 3.4 Standard treatment guidelines (STGs).Download from: http://www.scribd.com/doc/25528109

[3]. Duerden, M. \& Walley,T, 1999. Prescribing at the interface between primary and secondary care in the UK .Towards joint formularies? Pharmacoeconomics15 (5):43543. Available from: http://www.ncib.nlm.nih.gov/pubmed/1053796 (Accessed: $2013-$ 02-28).

[4]. Ross, S.M., Papshev, D., Murphy, E.L., Sternberg, D.J., Taylo,r J. \& Barg, R. 2005. Effects of electronic prescribing on formulary compliance and generic drug utilization in the ambulatory care setting: a retrospective analysis of administrative claims data. JManag Care Pharm 11(5):410-5. Downloaded from: http://www.ncbi.nlm.nih.gov/pubmed/15934800

[5]. Wade,W.E, Spruill, W.J, Taylor, A.T, Longe, R.L \& Hawkins, D.W. 1996.The Expanding Role of Pharmacy and Therapeutics Committees.The1990's and Beyond. Downloaded from: http://www.ncbi.nlm.nih.gov/pubmed/10163415

[6]. Shrank, W.H, Ettner, S.L, Glassman, P \& Asch, S.M. 2004.A Bitter Pill: Formulary Variability and the Challenge to Prescribing Physicians. The Journal of the American Board of Family Practise 17:401-407. Available from: http://www.jabfm.org/cgi/content/full/17/6/401 (Accessed: 2013-02-28

[7]. Tisocki, K., Ball, D., Laing, R.L., Hogerzeil, H., Mehta, D.K. \& Ryan, R.S.M. 2004.Developing National Formularies Based on the WHO Model Formulary. Downloaded from: http://www.powershow.com/view1/1b79b6

[8]. Mohanty BK, Aswin M, Hasamni AA, Murty KSN, Jena SK: Prescription pattern in the Department Of Medicine of a Tertiary Care Hospital in South India, IJCDR, vol. 4, issue, 1, page 2047-2051-2010

[9]. T.M.Vijayakumar, D.Sathyavati, T.Subhashini, S.Grandhi, M.D.Dhanaraju: Assessment of prescribing trends and rationality of drug prescribing, International Journal of Pharmacology, 7:140 -143-2011. Downloaded from: http://scialert.net/abstract/?doi

[10]. Potharaju, Hanumantha Rao, Kabra, S.G., Prescription audit of outpatient attendees of secondary level government hospitals in Maharashtra: Indian journal of Pharmacology, vol. 43, No.2, 2011, pp. 150-156. Downloaded from: https://www.google.co.in

[11]. Rishi RK, Sangeeta S, Surendra K, Tailang M: Prescription audit: experience in Garhwal (Uttaranchal), India. Downloaded from: http://www.unboundmedicine.com

[12]. Nazima Y. Mirza, Sagun Desai, Barna Ganguly: Prescribing pattern in a pediatric out-patient department in Gujarat, Bangladesh J Pharmacology 2009, 4: 39-42. http://www.researchgate.net/publication/26530323 